\title{
Dissent with modification: how postcreationism's claim of hyperrapid speciation opposes yet embraces evolutionary theory
}

\author{
R. Joel Duff ${ }^{*}\left(\mathbb{D}\right.$, Thomas R. Beatman ${ }^{2}$ and David S. MacMillan $\| I^{3}$
}

\begin{abstract}
The development of creationism to its multiple modern forms has been made possible in part by its appropriation and misuse of mainstream scientific terms. Here we illustrate how anti-evolutionary advocates have redefined the terms macroevolution and microevolution to advance their view of the origins of biological diversity. We identify and describe an ideological movement within modern young-earth creationism we call postcreationism, those that have embraced a hyperrapid speciation model of the origin of biological diversity. Postcreationism is demonstrated with specific examples from young-earth creationist publications and Ark Encounter creationist theme park, with takeaways for addressing these ideas in evolutionary biology education.
\end{abstract}

Keywords: Young-earth creationism, Creationist, Macroevolution, Microevolution, Evolution, Natural selection, Postcreationism, Ark Encounter

\section{Introduction}

Young-earth creationism, also known variously as literalday creationism, literal creationism, or creation science, is a movement dedicated to providing purportedly scientific support for a particular literal reading of the Biblical book of Genesis. Their reading of Genesis and subsequent attempts to gather evidence in support of their view puts them at odds with the scientific consensus on common descent and deep time. As such, Young-earth creationists (YECs) are the leading anti-evolutionary voices in North America (Chin and Buckland 2011).

Despite abundant evidence that the planet is billions of years old and that all living organisms share a common ancestor, YECs assert that the earth was formed supernaturally less than 10,000 years ago and that all forms

\footnotetext{
*Correspondence: rjduff@uakron.edu

${ }^{1}$ Department of Biology, University of Akron, Akron, OH 44325-3908, USA

Full list of author information is available at the end of the article
}

of living things, including humans, on earth were independently created at about the same time as the earth. In their description of natural history, the supernatural creation of lifeforms precipitated today's diverse biosphere, as the originally-created populations diversified into modern species. While the scale of this alleged postcreation diversification has changed over time, the current claim is that the original created populations served as independent common ancestors of entire taxonomic families (Belknap and Chaffey 2019), though in some cases represent at ancestry of greater or lower taxonomic ranks. In recent years, attempts to promote the validity of their explanatory models have led to YECs increasingly accepting the conventional mechanisms of biological evolution and broad common ancestry, departing from the comparative animus toward common ancestry exhibited by earlier generations of creationists.

Here we provide an introduction to a new-wave creationist viewpoint which has quietly spread through the insular world of young-earth creationism. We will

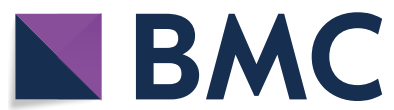

(c) The Author(s) 2020. This article is licensed under a Creative Commons Attribution 4.0 International License, which permits use, sharing, adaptation, distribution and reproduction in any medium or format, as long as you give appropriate credit to the original author(s) and the source, provide a link to the Creative Commons licence, and indicate if changes were made. The images or other third party material in this article are included in the article's Creative Commons licence, unless indicated otherwise in a credit line to the material. If material is not included in the article's Creative Commons licence and your intended use is not permitted by statutory regulation or exceeds the permitted use, you will need to obtain permission directly from the copyright holder. To view a copy of this licence, visit http://creativeco mmons.org/licenses/by/4.0/. The Creative Commons Public Domain Dedication waiver (http://creativecommons.org/publicdomain/ zero/1.0/) applies to the data made available in this article, unless otherwise stated in a credit line to the data. 
demonstrate that the modern YEC approach to descent with modification and common ancestry has become in some ways more similar to the modern evolutionary synthesis than YECs wish to acknowledge, often without any awareness among the movement's lay followers.

As a means of introducing the reader to this newwave of young-earth creationism and how it has taken root, we begin by illustrating how creationists have misappropriated the terms microevolution and macroevolution in advancing their alternative theory of the origin of species. In creationist-specific journals and popular literature, YECs make organized and concerted attempts to synonymize the term 'macroevolution' with the broader scientific consensus on deep time and universal common descent. Their goal in this is to bifurcate their lay audience's understanding of biology, creating the impression that there are "microevolutionary processes" which are somehow different from or unrelated to the rest of evolutionary biology. By targeted use of these terms, they are able to insist to their followers that they reject broad evolutionary theory as "macroevolution" while quietly appropriating the conventional mechanisms of biological evolution as "microevolution" wherever it suits them.

In contrast, the understanding of these terms within the mainstream scientific community does not feature the qualitative distinction claimed by creationists. While there are no universally-held definitions for all these terms, Box 1 provides definitions from a few popular sources of evolutionary terminology. Most biologists agree that microevolution can be broadly identified as the small, gradual changes to heritable alleles which take place within populations, such as natural selection, genetic drift, mutation, and gene flow via migration. In contrast, macroevolution is understood to reference evolutionary change taking place at or above the level of the species, involving the compounded effects of microevolutionary processes.

There is, of course, considerable debate among biologists about macroevolutionary processes. Differences of opinion among evolutionary biologists emerge readily when navigating the relationships of microevolutionary processes to macroevolutionary patterns, including the effects of mass extinctions, adaptive radiation, convergent evolution, coevolution, and punctuated evolution (Allmon 1994; Grantham 1995; Stanley 1979). In some cases, evolutionary biologists have debated whether macroevolution merely constitutes multiple compounded rounds of microevolution or represents a greater phenomenon (Erwin 2000). These disputes, however, overlay a universal consensus that "macroevolution" as a descriptor refers to changes that occur above the level of a species.
Unfortunately, this continued debate within modern biology, coupled with the inherent ambiguity in the definitions of these terms, can be used to perpetuate public misconceptions about evolutionary theory (Novick et al. 2014). This has led some biologists such as Bergstrom and Dugatkin (2016), who have written a general evolutionary biology textbook, to encourage broad avoidance of terms like "microevolution" and "macroevolution" rather than permitting confusion. However, the continued use of these terms by biologists and their aggressive appropriation by YECs has made public misunderstanding unavoidable.

Due to the lack of consensus definitions and willingness to broadly oversimplify in their representations of biological processes, the terms "microevolution" and "macroevolution" are used by YECs at the popular level to promote their own views. In their popular messaging, YECs present and discuss these terms with the implicit representation that they are providing accepted, wellestablished definitions and distinctions from within mainstream science:

"Evolutionists [the YEC term for those who understand and accept evolutionary theory] assume that the small, horizontal microevolutionary changes (which are observed) lead to large, vertical macroevolutionary changes (which are never observed)" (Morris 1996).

"There is, in fact, no known relationship between socalled microevolution and macroevolution." (Menton 1994).

"[M]acroevolution is not observable, repeatable, or refutable and thus does not qualify as either a scientific fact or theory." (Menton 1993).

The third quote from Menton above illustrates the underlying argument they seek to promote by bifurcating microevolution and macroevolution. As demonstrated by Fig. 1, YECs argue that "observable and repeatable" heritability in biology are merely examples of microevolution, while the mainstream proposal of "macroevolution" is an unsupported, illegitimate theory which runs counter to observable facts.

This purported distinction between "microevolution" and "macroevolution" mirrors a greater rhetorical approach favored by YECs. This approach divides fields of scientific inquiry using distorted forms of "operational science" and "historical science" (Geisler and Anderson 1987) so as to provide a framework for their denial of numerous scientific consensuses. Other examples of YECs partitioning of fields of inquiry include treating forensics, seismology and meteorology as operational 


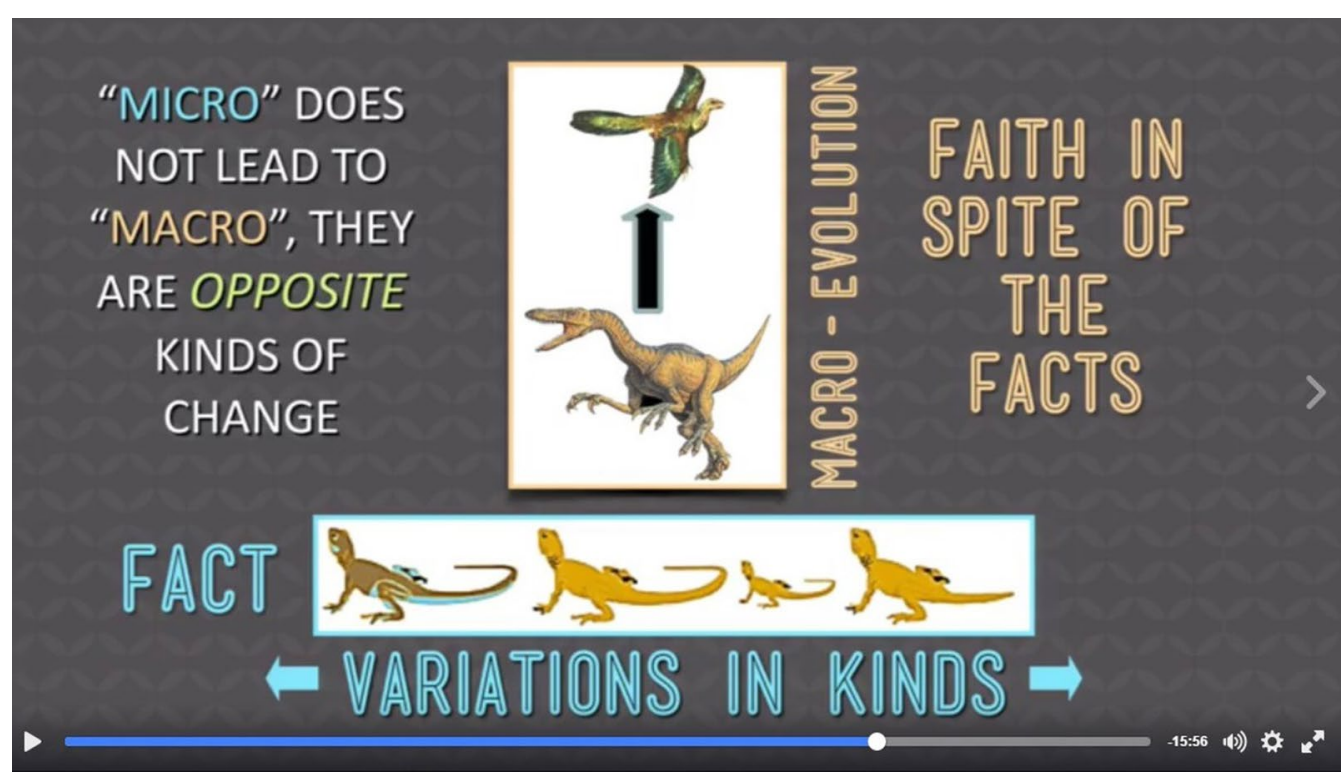

Fig. 1 Screenshot from a public Facebook presentation given by a speaker, Bryan Osborne, at the young-earth sponsored Creation Museum in Kentucky. Here we see a typical presentation of the differences between macro and microevolution. (Osborne 2016)

sciences while their counterparts paleontology, tectonics and paleoclimatology are treated as "historical" sciences and therefore not trustworthy.

While the scientific community does recognize differences in how the scientific method informs our understanding of natural law and how it informs our understanding of the past, the distinction advanced by YECs does not reflect these valid distinctions that exist within mainstream science (Cleland 2002; Jeffares 2008). Furthermore, mainstream science generally holds a positive rather than a negative connotation with respect to our confidence in historical science (Currie 2018).

"Philosophers of science draw a distinction between research directed towards identifying laws and research which seeks to determine how particular historical events occurred. They do not claim, however, that the line between these sorts of science can be drawn neatly, and certainly do not agree that historical claims are any less empirically verifiable than other sorts of claims." (Rosenau 2008)

YECs insist on strict separation between microevolution and macroevolution, asserting that their distinctions represent a real divergence in mainstream science. However, they conspicuously avoid providing definitional clarity that would clarify this purported distinction. Based solely on the definitions provided by YECs, one could conclude almost anything about their concept of microevolution. For example, it would be impossible to determine from their definitions alone whether their concept of "microevolution" permits the emergence of new subspecies or species, because their definitions are built around tautological rhetoric rather than scientific rigor.

Although the definitions used by YECs intentionally obscure their underlying concept of biological diversification, examining their actual positions on diversity reveals that their version of "microevolution" includes not only speciation, but descent with modification from a common ancestor at the level of the taxonomic family or higher. In some cases, they even accept that a single breeding pair from an ancestral species could undergo enough repeated speciation to give rise to an entire mammalian order (Lightner 2012; Ark Encounter 2016). Such apparent embrace of mainstream evolutionary biology is counterbalanced by their insistence that such broad diversification would still be considered "microevolution" by mainstream scientific standards, as well as the emphatic insistence that any common ancestry above this arbitrary level is categorically impossible. They also assert that these seemingly evolutionary changes took place on an exponentially aggressive timescale, far more rapid than actual biological processes permit.

In order to better understand the semantic and rhetorical puzzle of YEC teachings, we explore YEC views of the origins of biological diversity using one of their most prominent educational enterprises, the Ark Encounter. The Ark Encounter is a \$100 million theme park centered 
on a purportedly full-scale representation of Noah's Ark, based on and promoting as fact YEC interpretations of the Genesis narrative in the Bible (Bielo 2018). As one of the leading Christian-themed attractions in the world, it attracts as many as 1 million visitors per year (Knight 2018) and influences millions more through educational materials from its sponsoring organization, Answers in Genesis, the leading Christian YEC ministry.

Given that legitimate natural history and science museums in the same region have similar visitation rates, the Ark Encounter can have a significant impact on the public's understanding of the origins of biological diversity. The displays at the Ark Encounter and other YEC educational materials produced by its parent organization promote a strikingly different view of the origins of biological diversity than what is presented in most classrooms and natural history museums. Many students in public and private universities and high schools may have visited the Ark exhibition or been exposed to its teachings, placing instructors at a disadvantage. In this paper, we show how a robust understanding of the YEC views taught at the Ark Encounter can aid science educators in effectively promoting an accurate understanding of natural selection and the patterns of evolution.

Below, we use the example of carnivoran cladistics to show how creationist presentations of microevolution and macroevolution diverge from the scientific consensus and how changes in YEC viewpoints provide expanded opportunities for more effective science education. We detail how this knowledge can be used to advance better instruction in classrooms and correct public misconceptions about biology and about science in general (Senter 2010).

\section{Box 1: Common definitions of macroevolution}

"Evolution occurring above the species level, including origination, diversification, and extinction of species over long periods of evolutionary time." Evolution: Making Sense of Life 2nd edition (Zimmer and Emlen 2015)

"A vague term, usually meaning the evolution of phenotypic changes, usually great enough to place the changed lineage and its descendants in a distinct genus or higher taxon." Evolutionary Biology 4th edition (Futuyma and Kirkpatrick 2017)

"Large evolutionary change, usually in morphology; typically refers to the evolution of differences among populations that would warrant their placement in different genera or higher-level taxa." Evolutionary Analysis 3rd edition (Freeman and Herron 2004)
"Microevolution happens on a small scale (within a single population), while macroevolution happens on a scale that transcends the boundaries of a single species. Despite their differences, evolution at both of these levels relies on the same, established mechanisms of evolutionary change." UC Berkeley website; Understanding Evolution. (UC Berkeley 2019)

"Macroevolution can be defined simply as evolution above the species level, and its subject matter includes the origins and fates of major novelties such as tetrapod limbs and insect wings, the waxing and waning of multi-species lineages over long time-scales, and the impact of continental drift and other physical processes on the evolutionary process." From: Symposium on Macroevolution (Jablonski et al. 1997)

\section{The evolution of creationism}

The form of creationism commonly encountered by scientists and science educators today in North America is a relatively recent development. Many creationists prior to the twentieth century, including the diluvialists or Mosaic geologists of the nineteenth century, had no particular dispute with deep time or the mainstream geology of the day. Rather, religious objections to deep-time and eventually Darwin's theories had more to do with broad religious ideas about human identity and God's role in the universe. Some opposed the idea of common descent because they felt it took God out of the process of creation; some further protested the revolutionary notion that the various races of humankind shared a biological origin. (Numbers 2006; Scott 2012)

Just as pseudoscience today presents a diversity of forms, so the opposition to Darwin and deep-time geology was not monolithic in the nineteenth and early twentieth centuries. Today, one specific form of science denial has gained a strong foothold among a large segment of evangelical Christianity. This organized evangelical antievolution movement was still nascent at the time of the Scopes "Monkey Trial" in 1925, drawing most of its strength from its general opposition to Darwin's Descent of Man and the teaching of the common ancestry of humans and other great apes. However, the foundations for its eventual coalescence had been laid 2 years prior in the work of Seventh Day Adventist George McCready Price and his book The New Geology (Price 1923).

Early biological creationism maintained the pre-Darwinian position of species fixity. Observable artificial selection, which had been explored by Mendel in the decades prior to Darwin, was understood as a temporary, artificially-induced departure from the essential nature of each species. This viewpoint maintained strength within 
the creationist community for many years, even into the late twentieth century. For example, Morris (1974) in Scientific Creationism states, "Many varieties of dogs have been developed from one ancestral dog 'kind,' yet they are still interfertile and capable of reverting back to the ancestral form." (p. 180)

Yet a broader understanding of the origin of species had already begun to emerge. In 1941, Seventh Day Adventist and botanist Frank Marsh (1941) proposed that limited speciation was possible within certain bounds. Those limits were identified with the kinds of organisms that God had originally created, as described in Genesis. This tentative acceptance of speciation allowed for limited common ancestry and gave creationists justification for accepting that some species had formed through adaptation to new environments since the creation or since departing Noah's Ark.

In 1961, mechanical hydrologist Henry Morris and theologian John Whitcomb joined forces to recapitulate Price's book in their breakout work The Genesis Flood (Morris and Whitcomb 1961). Through that book, many of the modern features of young-earth creationism found a foothold in the broader evangelical community. Primarily focused on Flood Geology as a geological theory of the earth's history, The Genesis Flood took a strong stance against evolution, but avoided providing any clear hypothesis for the origin of biological diversity or guidance on what level of biological diversification was permitted. But as late as 1982 Morris and Parker in "What is Creation Science?" (1982) were still making claims such as "No one has ever documented the development of a more complex 'species', let alone a new genus or family!" These were the earliest inklings that organisms could adapt and speciate to fill the world following a global Flood. However, the extent of adaptation and speciation allowed by these early adopters of twentieth century creationism was wholly unlike that seen in twenty-first century creationism.

A growing segment of today's young-earth creationism promotes a radical extension of this "diversification within kinds" model for the origin of the diversity of life on Earth. The limited common ancestry accepted by Marsh, Whitcomb, and Morris has been greatly expanded, broadening each kind and dramatically reducing the total number of species purportedly created by God. Remarkably, this particular brand of creationism borrows heavily from the instruction found in any typical evolutionary biology textbook. They readily affirm that all life on earth has undergone descent with modification. They affirm that most or all extant species-with the notable exception of Homo sapiens-are related to numerous other extant or extinct species via common ancestry. They further admit that speciation from those common ancestors has occurred via observable and testable evolutionary mechanisms such as genetic drift and natural selection, albeit occurring at an exponentially inflated rate. Despite acceptance of these broad evolutionary principles, however, they carefully avoid using the term "evolution," which they synonymize with deep time, Big Bang cosmology, abiogenesis, and universal common descent, instead describing their view as "microevolution" or mere "adaptation".

Predictably, this updated YEC origin of species has several significant points of departure from conventional evolutionary theory. Their conception of natural selection enjoys virtually no constraints on how quickly it can produce new species. Yet they reject universal common ancestry of all species, proposing essential limitations on both the historical extent of common ancestry and each organism's innate potential for further diversification of its offspring. This YEC model of biological origins has been called the creation orchard (Wise 1990) and is likened to an orchard of life rather than a single tree of life. Each "tree" in the orchard represents a uniquely created kind which has evolved in almost every instance to have many different branches.

While this "creation orchard" representation has existed from early in the history of creationism, the consistent trend has been a reduction in the number of "trunks" and a corresponding explosion in the number of branches within each tree. These are the increasingly broadening collections of species which are admitted to share common ancestors and which are believed to represent original created kinds. See Box 2 for additional principles of the modern YEC biological origins model, which has been internally described as "baraminology" (from baramin, coined by Frank Marsh, a malaprop portmanteau of the transliterated Hebrew bara for "creation" and $\min$ for "kind").

Prominent YEC promoters today roughly equate a kind to the taxonomic level of Family, though there are numerous examples where this scope is widened or narrowed (Lightner 2012; Duff 2016a). They accept that genetic variation is the raw resource necessary for species to adapt and speciation to occur, but reject the scientific consensus that the successive accumulation of mutations over time provide an ongoing source of genetic variation. Rather, they propose that excess genetic variation was supernaturally pre-loaded into the common ancestors of living species by an act of miraculous creation and expressed through an accelerated, poorly-understood version of natural selection.

Possibly the most striking departure between conventional evolutionary theory and this YEC origin of species is the pace at which they believe evolutionary 
mechanisms can create new species (Lightner et al. 2011). In contrast to the findings of mainstream biology, they propose that all extant land vertebrate species descended from a small population of precursors-the Ark kindsby modification and accelerated speciation since Noah's Flood (Duff 2016a) via standard evolutionary mechanisms (Duff 2016b), resulting in the formation of tens of thousands of new species in just a few thousand years. In their popular messaging, YECs point to observed speciation events reported by mainstream science as evidence of biological potential for rapid speciation, but have given comparatively little attention to advancing viable mechanisms for this form of natural selection.

It is not surprising to find that they themselves recognize their own models as a form of "rapid" or "hyper" speciation relative to the conventional understanding of speciation rates (Jeanson and Lisle 2016). We have labeled the new generation of YECs that have embraced broad, rapid macroevolution via mechanisms of evolution working at accelerated rates as postcreationist. Descriptors for this creationist model of biodiversity origins has included: post-diluvial hyper-evolution, radical accelerated diversification (RAD) or Post-Flood Hyper-Evolution (Duff 2016a; MacMillan 2015; Whorton 2005). As will be shown, young-earth creationists depend on their rhetoric being perceived as "consistent" or "unchanging" and thus they would dispute any implication that their views have departed significantly from earlier conceptions. However, the qualitative shift in their synthesis, particularly with respect to the degree of evolutionary change they now accept, places the new youngearth creationists' model firmly beyond the creationism recognized by their predecessors.
Before describing the origins and implications of the transition to postcreationism, it is essential to understand the profound difference between biological origins as taught by creationist organizations and as understood in conventional evolutionary theory. We illustrate this distinction here through the study of canid origins as the YEC organization Answer in Genesis depicts in their Ark Encounter theme park. They claim that all 36 extant (still-living) species of canids (foxes, wolves and domestic dogs, etc.) along with dozens of extinct species all evolved from a single ancestral pair-a created Ark kind-in less than 4500 years. Evolutionary biologists studying the evolution of canids have concluded that all canids do indeed share a common ancestor, but one which lived no less than 12 million years ago (Nyakatura and Bininda-Emonds 2012). Even wolves and coyotes, which are considered relatively "young" species, are understood to have been separate species for over one million years (Nyakatura and Bininda-Emonds 2012). These conclusions are based on fossil evidence, geographic distribution, comparative anatomy and the observed similarities and differences in the respective genomes of the clade. Contrasting this conventional understanding of the history of canids, the postcreationist teaching that all of these species formed through their proposed mechanisms within the past 4500 years is a dramatic departure.

Befitting their alternative view of origins, postcreationists have expanded an existing YEC lexicon for the origins and classification of biological diversity called baraminology (Table 1). The basic unit of baraminology is a "baramin" which is equivalent to kind. What constitutes the biological boundaries of a kind of organism is a topic of considerable debate in the creationist' literature

Table 1 Terminology in the postcreationist origin of species (Wise 1990)

\begin{tabular}{|c|c|}
\hline Terms & Definition \\
\hline Baraminology & The identification and study of biblical kinds (baramins), equivalent within postcreationism to biological systematics \\
\hline $\begin{array}{l}\text { Baramin or "Created Kind" or } \\
\text { "Biblical Kind" or Kind }\end{array}$ & $\begin{array}{l}\text { The fundamental biological unit of postcreationism, roughly comparable to a genus- or family-level clade in } \\
\text { mainstream taxonomy. Successful hybridization of two extant species is considered sufficient but not necessary } \\
\text { evidence that they are members of the same baramin }\end{array}$ \\
\hline Holobaramin & $\begin{array}{l}\text { The totality of members of a single baramin, including extant, fossil, and extinct varieties and individuals. Equivalent } \\
\text { to a monophyletic clade }\end{array}$ \\
\hline Archeobaramin or "Original Pair" & $\begin{array}{l}\text { The most recent original population from which all extant members of a baramin descended. The archeobaramin for } \\
\text { each terrestrial vertebrate baramin is associated with 2-14 individuals on the Ark during the flood; the archeobara- } \\
\text { min for other baramins is associated with the original populations of the Genesis Creation Week. Equivalent to the } \\
\text { common ancestor of basal clade }\end{array}$ \\
\hline Microevolution & $\begin{array}{l}\text { Descent with modification by standard biological processes, resulting in diversification which may include speciation } \\
\text { within a single holobaramin }\end{array}$ \\
\hline Macroevolution & $\begin{array}{l}\text { Evolutionary change sufficient to generate a novel kind. Often depicted by postcreationists as a member of one kind } \\
\text { transitioning into membership within another kind; purported necessary to permit universal common descent. Also } \\
\text { used synonymously with the theory of universal common descent as well as more broadly, including abiogenesis; } \\
\text { often referred to colloquially as "molecules to man evolution" or "from goo to you by way of the zoo" (Hill et al. 1985) } \\
\text { in YEC rhetoric }\end{array}$ \\
\hline
\end{tabular}


(Wise 1990; Wood et al. 2003; Wood and Garner 2009; Wood 2006), despite the postcreationist claim that it is the core of biology and places hard limits on evolutionary change. It is worth noting that in constructing their own terminology they have only served to rediscover the nested hierarchical pattern of life (baramin $=$ crown group, archaeobaramin=stem group, and holobara$\min =$ monophyletic clade) which evolutionary theory so effectively explains.

\section{Box 2: Assumptions and principles of modern YEC biology}

- Many phenotypically similar species may share common ancestry via an "original created kind" or baramin, but descendants of each "original kind" cannot share common ancestry with descendants of any other "original kind."

- Populations of the original created "kinds" (baramins) can undergo "microevolution" (natural selection, genetic drift, and deleterious mutations that cumulatively result in speciation events), but are never able to gain "new information" through this process. (Senter and Mackey 2017)

- Biological limits on evolutionary mechanisms preclude macroevolution and common descent, which would require genotypes not present in the genome of each "original kind."

- All changes to organisms have happened within the last 6 to 10,000 years

- A global flood killed all but 2-14 representatives of each "original kind" of land-living vertebrate organisms about 4500 years ago.

- All extant land vertebrates within each "original-kind" clade (monobaramin) are descended from no more than 14 members of that clade that were preserved during the Noahic Flood bottleneck within the last 4500 years.

\section{Postcreationist theory of biological origins as represented on the Ark Encounter}

As Answers in Genesis worked to complete their Ark Encounter theme park in northern Kentucky, they made a concerted and systematic effort to model their educational displays according to a rigorous interpretation of baraminology. Postcreationists Jean Lightner and Jon Ahlquist explain the nuance in their taxonomy:

"Although creationists reject universal common ancestry on biblical grounds they still need to adequately account for the diversification and speciation that has occurred with the various kinds of animals since the Flood. Because the biblical model demands the rapid diversification of creatures into forms filling different ecological niches, or adaptive radiation, creationists have the opportunity and responsibility to contribute to our understanding of this important topic and thus show the relevance of the biblical model." (Lightner and Ahlquist 2017)

Because YECs believe that "every land-dwelling, airbreathing animal in the world today owes its existence to its Ark ancestors" (Belknap and Chaffey 2019), they are driven to consolidate as many extant species as possible into broader and broader parent groups-the baramins or created kinds of their systematics. This is primarily the result of space limitations in Noah's proposed vessel. The smaller the menagerie purported to have been contained in the Ark, the more feasible the whole narrative becomes (Woodmorappe 1996), and so postcreationists feel pressure to come up with ways that the vast array of extinct and extant land-dwelling vertebrate species (all other animals including aquatic vertebrates, plants, fungi, and innumerable protists and bacteria would have had to fend for themselves during the global deluge) could have been represented by the lowest possible number of Ark pairs-possibly as few as 1400 archeobaramins or basal ancestral pairs (Ham 2019).

As postcreationists struggled to build out their new taxonomy (Lightner et al. 2011, Wood 2013), the challenges they faced provide a surprisingly clear picture of exactly where their pseudoscience breaks down. How does the young-earth creationist distinguish the boundary between microevolution and macroevolution? Postcreationists have generally avoided any definite answer to this question, other than to insist that there can never be any overlap between separate baramins or any ancestral heritage shared between groups. This hard line is defended using a caricature in which "microevolution" and "natural selection" are depicted as a subtractive process while "macroevolution" is depicted as an additive process (Fig. 2).

As discussed above, possibly the most common example of the limits of common ancestry and thus the distinction of kinds, provided by even the earliest creationists, is the difference between dogs and cats. The diversity of dog breeds, they explain, is the result of microevolution, or variation among a large population of canids, then expanded to include all dogs, dingoes, and wolves. Postcreationists have now further expanded this baramin to include genera as diverse as Vulpes, Lycalopex, Chrysocyon, Urocyon, and Nycereutes, as well as numerous extinct canid genera. Their example, however, denies that any member of the dog 


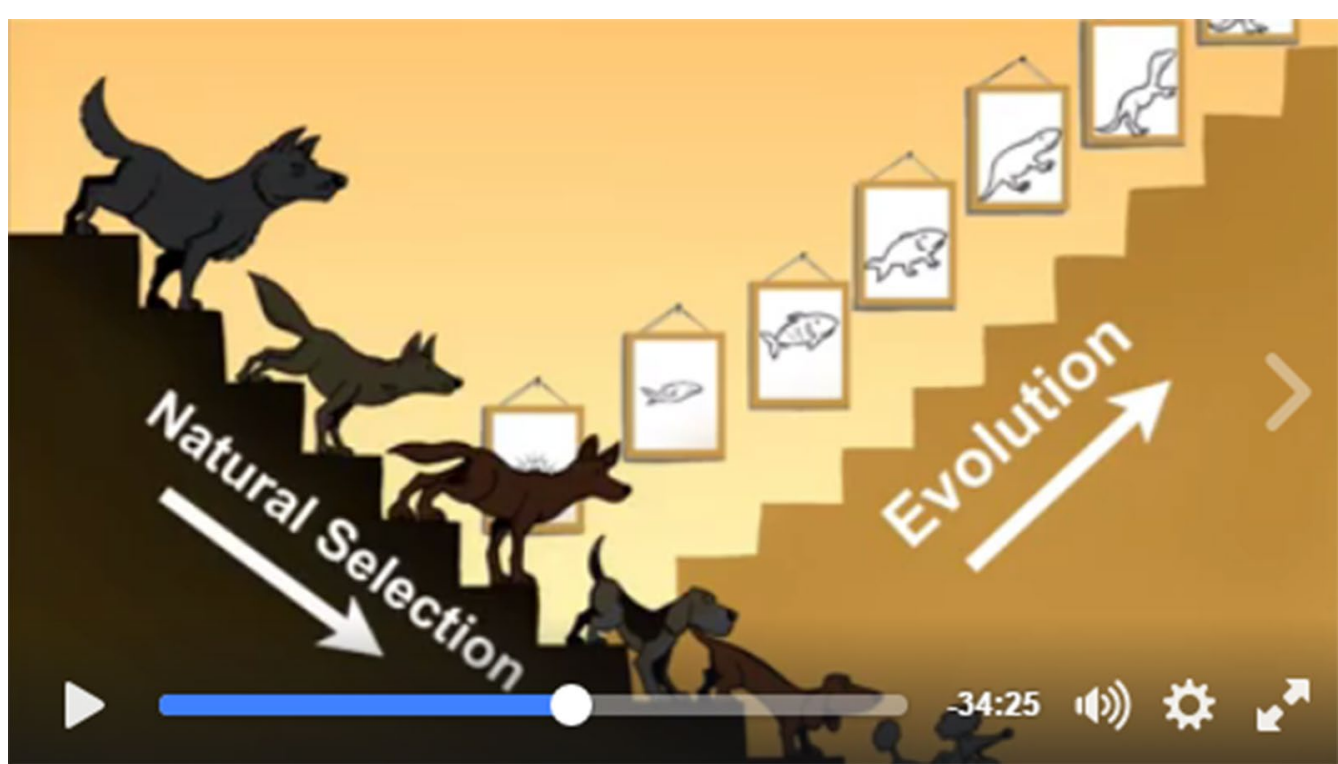

Fig. 2 Screen shot from an Answers in Genesis' Facebook presentation July 2016 illustrating change within kinds as degradation of information and change between kinds - their definition of macroevolution —as requiring gains in information and always requiring an "upward" trajectory. This cartoon, featured in several of Ken Ham's well-known presentations, depicts the creationist view of "microevolutionary" speciation. They say: "You can breed wolves to get to chihuahuas, but you can't breed chihuahuas to get wolves—variation in the genetic information has been lost." (Patterson 2008)

kind could ever evolve into a member of the cat kind or possibly share common ancestry with a member of the cat kind. They typically assert that microevolution is characterized by a loss or filtering of genetic information, moving from a more complete genome to a restricted one; their conception of macroevolution (e.g., to get from a dog to something like a cat) would require adding new information to the genome and is therefore claimed to be impossible.

This conception is exemplified by an explanation provided in an interview by Doug Henderson, the lead exhibit designer at the Ark Encounter:

Just like, you know, you've got dogs. You don't need all the varieties of dogs, you just need two dogs, and then you breed out everything else. So the same thing is true with all of the animals, so that's why the Bible specifically says kinds. (We Believe in Dinosaurs 2019)

This comparison of dogs and cats provides a simple, readily-accessible rule suitable for the lay audiences courted by Answers in Genesis and other creationist groups. It is easy to remember: small changes "within a kind" are natural, observable variation (and part of God's plan); large changes-implying easily observed differences in distinguishing features-"between kinds" are evolutionary nonsense with no evidence. Examples are commonplace across messaging platforms.
For example, Fig. 3 shows a typical tweet by Ken Ham, $\mathrm{CEO}$ of Answers in Genesis, shared with his followers in 2018 (Ham 2018).

It is difficult to determine whether postcreationists are aware of the errors in these sorts of arguments. Ken Ham is not a trained scientist. However, he employs a Harvard Ph.D. biologist on his staff, so he should be in a position to understand that the visible similarity between wolves and coyotes obscures a far greater genetic diversity than that between terriers and Great Danes. He continues to repeat this rhetoric of kinds, with its limitation on microevolution leading to macroevolution, because it proves highly convincing to the millions of evangelical Christians who view evolutionary biology with suspicion or animus. This remains effective despite the fact that the postcreationist' acceptance of greater inclusiveness of kinds requires increasingly deeper common ancestry to be true. To use the "creation orchard" representation, postcreationists have replaced a large orchard of saplings with a handful of tightly-packed bristling shrubs: the "postcreationist hedge".

Answers in Genesis and YEC journals have published large, detailed lists of various species, families, and orders with attempts to organize them according to the new creationist taxonomy (Hennigan 2013, 2014; Lightner 2012). One such article by Lightner (2012) organizes the majority of Order Carnivora into a total of 18 (12 extant and six extinct) distinct land-dwelling baramins (not including 


\section{Ken Ham}

@aigkenham

\section{The wolf \& coyote are different species \& evolutionists claim this took thousands of years, yet the differences between the Great Dane \& Yorkshire Terrier are much greater but they are the same species \& we know were bred in the last few hundred yrs. Evolution is bankrupt}

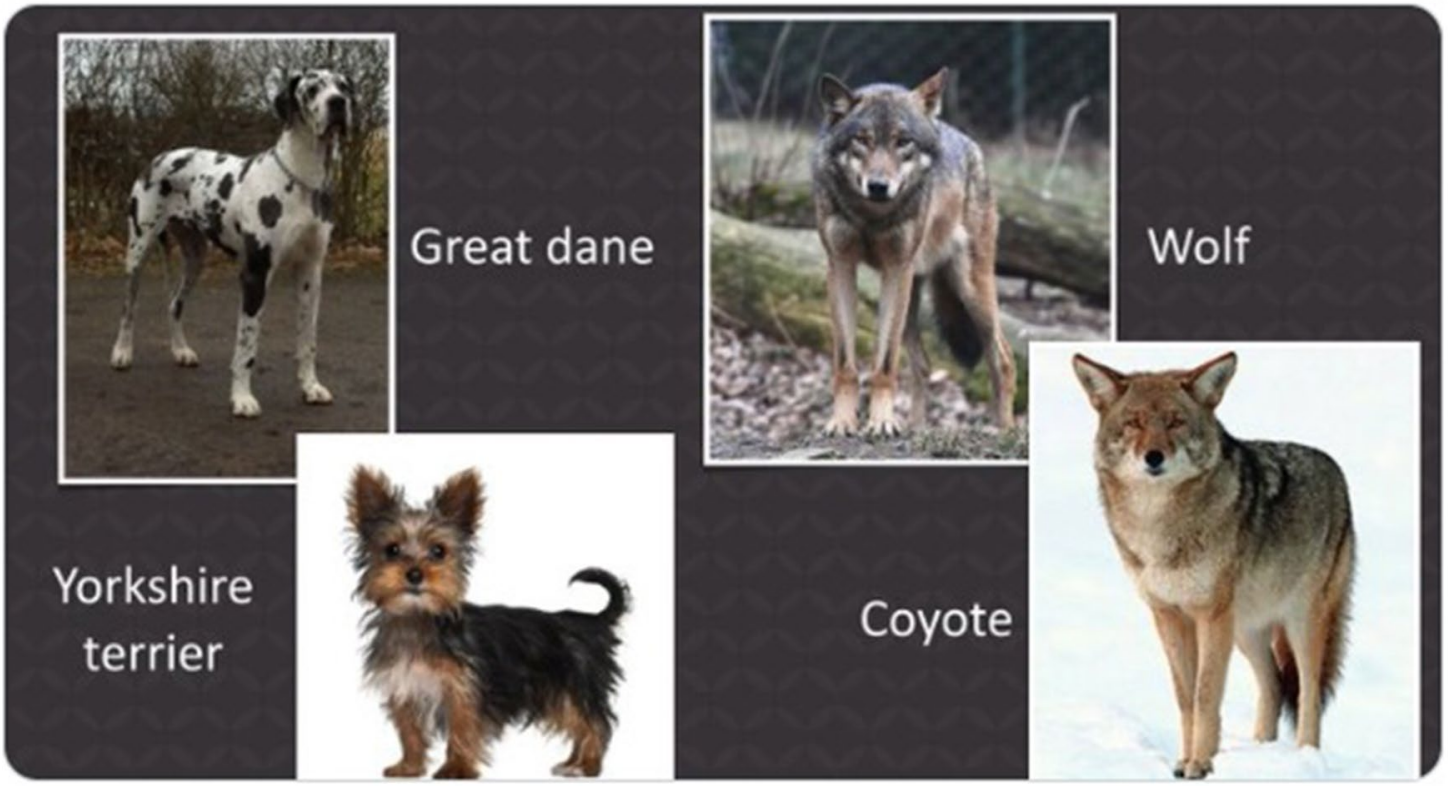

\section{7:17 AM - Mar 12, 2018 - Twitter Web Client}

Fig. 3 Screenshot of tweet from CEO of Answers in Genesis, Ken Ham, illustrating confusion between morphological and underlying genetic change and the time-scales of natural and artificial selection (Ham 2018)

the aquatic carnivores including seals, walruses, and eared seals, which she believes did not need to be preserved on the Ark). Conveniently for postcreationists, this means the $\sim 250$ extant terrestrial carnivoran species (plus at least 300 extinct species including at least six families that are entirely extinct today) would be represented by only 36 individuals from 18 kinds (12 extant and 6 extinct) on the Ark, as depicted in Fig. 4.

Almost all creationists agree that all information in the genome ultimately traces back to a supernatural author, rather than being introduced into lineages by the iterative process of mutation and natural selection. Most postcreationists require that any functional sequence in the genome of species must have been present in the original archeobaramin (basal population), with all diversification and speciation taking place as a result of information filtering and loss. This requires each individual in the archeobaramin have been the repository of all the genetic information that would be necessary for all of its descendant lineages, which may include dozens or even hundreds of modern species.

Thus, the process of building out models for each "original pair" demonstrated the essential vulnerability in the postcreationist framework. Combining the characteristics of all extant and extinct felids to form a super-cat, all extant and extinct ursids to form a super-bear, and so forth produces a speculative morphology for each pair on the Ark. In many cases, they even borrow from 


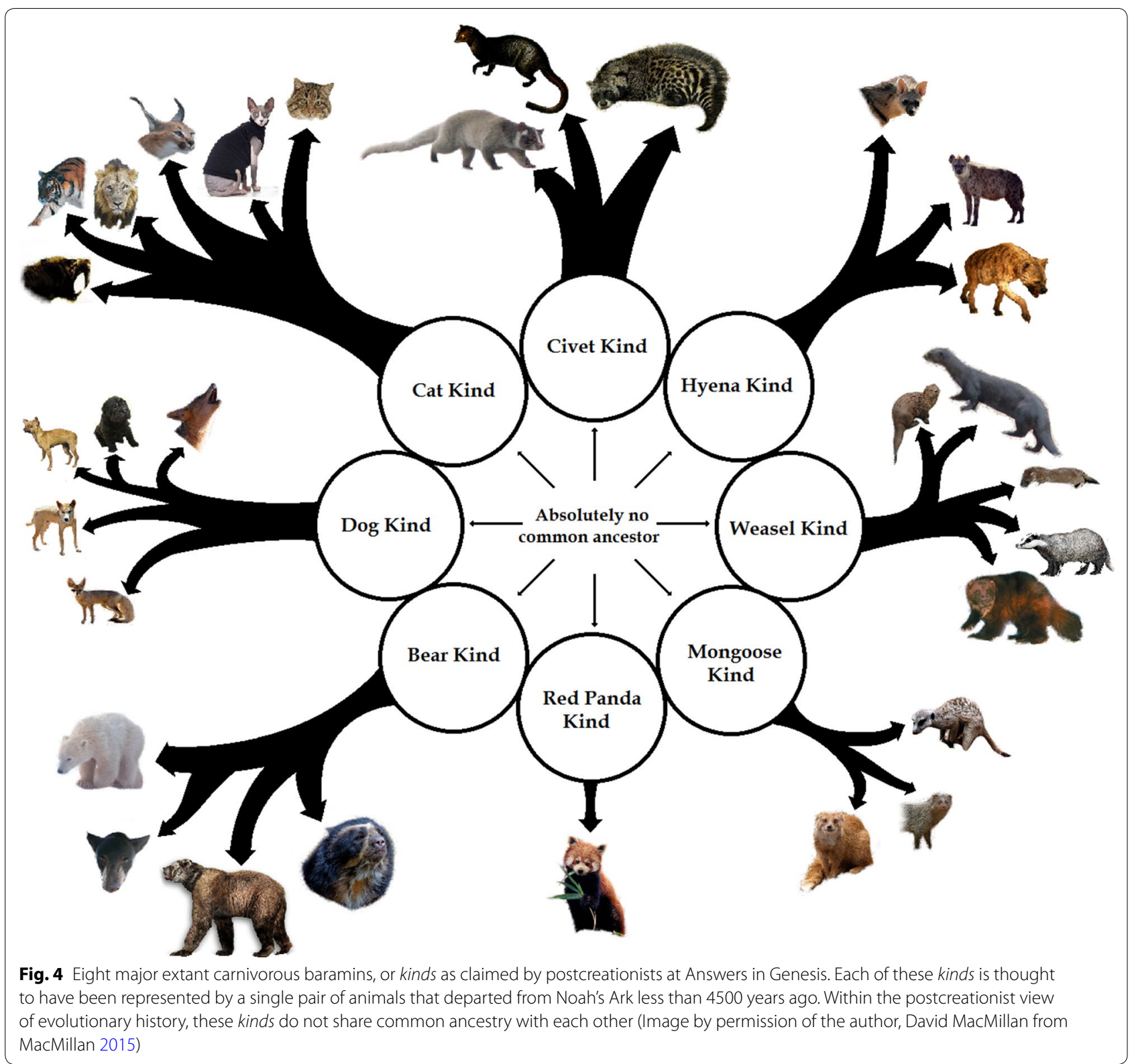

conventional paleontology in describing the proposed ancestors of each taxonomic family.

In taking this approach, postcreationists are essentially rediscovering basic morphological phylogeny. While still claiming that the various baramins all have intrinsic, essential differences that render them totally unique and distinct from one another, they have arrived at a selection of representative progenitors for each which display a high degree of morphological similarity (Fig. 5). There is generally more morphological and genetic variation within each of the individual kinds identified by Answers in Genesis than within the collective group formed by their ancestors.
Such a conclusion comes as no surprise to evolutionary biologists. Because carnivorans are generally understood to be a monophyletic group, it is expected that an examination of morphological phylogeny would reveal greater and greater similarity as the group approaches its most recent common ancestor, the miacids (Heinrich et al. 2008), and more and more diversity as the clade descends from this ancestor. It is only natural for mainstream scientists to understand that species variation within any given modern carnivoran family is greater than the variation among the original group of carnivoran ancestors, as creationists are now unwittingly demonstrating. 


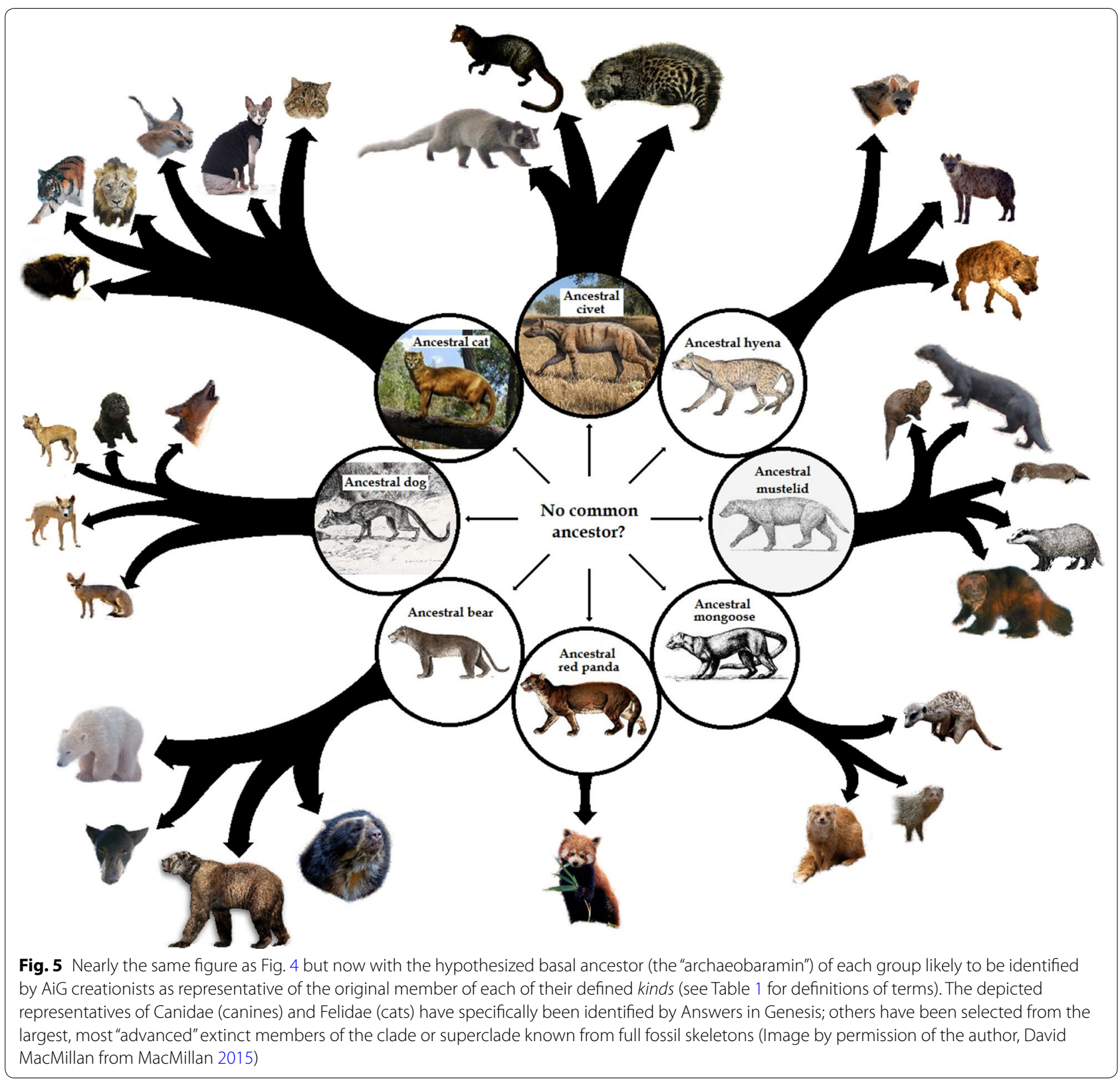

With respect to the genetic distance between species within carnivore families and the genetic distance between the common ancestors of each family and the single common ancestor of the order carnivora, Answers in Genesis molecular biologist Nathaniel Jeanson (2015) produced a phylogeny of carnivores based on mitochondrial DNA sequences. That phylogeny showed longer branch lengths (more genetic distance) between some species within a single family than the branch lengths connecting the common ancestors of each family to their universal common ancestor. Despite including those ancestral connection in his phylogeny-because he was using DNA sequences and a program that assumed common ancestry-Jeanson denies the connection among the carnivore families and claims only that the diversity within a single kind is the result of microevolution.

In fact, Jeanson and Lisle (2016) recognize yet another challenge to the postcreationist paradigm: they have identified no breaks or barriers to prevent the eventual emergence of species so different that, if compared, would certainly be viewed as representing different original kinds. They state: "hence, robust YEC explanations for the origin of a vast number of species must explain not only how genetic mechanisms 
produce many phenotypes, but also how these processes did not transform one kind into another." Thus postcreationists, in their attempts to show scientific rigor, unwittingly uncover the very mechanisms that prove the opposite of their model. If they cannot identify a barrier to a modern species producing descendants which would by their method appear to descend from different original kinds, they cannot effectively argue that two species they currently consider to represent distinct kinds might not have originally diversified from a single ancestral clade.

Placing this postcreationist "research" within the framework of mainstream cladistics demonstrates how similar their pattern of change within kinds is compared to mainstream evolutionary biology and offers an opportunity to expose the caricatures in postcreationist rhetoric. Although the terminal branches of the tree in Figs. 4 and 5 are explicitly affirmed by postcreationists under the auspices of microevolution, the union of those branches into a single tree would be denied as macroevolution. Yet this gives the lie to their common description of macroevolution as "one kind changing into another." Hyenas are not turning into dogs and bears are not turning into weasels; rather, the thing creationists call macroevolution is simply the accumulation of the same diversification they affirm as microevolution.

Ironically, postcreationists have shown repeated willingness to join existing "microevolutionary" branches together into what they would have formerly had eschewed as macroevolution. Postcreationists have joined foxes, dingoes, and maned wolves into the existing "dog" kind (Numbers et al. 2004). They have also abandoned early creationist views on the origins of felids, first joining lions and tigers to the lineage of domesticated cats, then including saber-toothed cats and other prehistoric felids.

YECs have spent years insisting cats, dogs, hyenas, and bears (along with numerous other families) are all separate, distinct kinds and don't share a common ancestor. Despite past reticence to acknowledge the common ancestry of carnivorans, the postcreationist tendency for greater inclusiveness of kinds over their predecessors might lead us to wonder whether the trend will continue, with the carnivoran "baramins" being combined further into a single consolidated carnivore kind which survived the Flood as a single pair on board Noah's Ark and thereafter multiplied into the many species shown above. But, to do so, they would have to explain how a single common ancestor for all carnivores is a form of "extended microevolution" (Fig. 6) if they wanted to keep insisting that "macroevolution" is impossible.

There are already indications of movement in this direction. For example, some creationists have

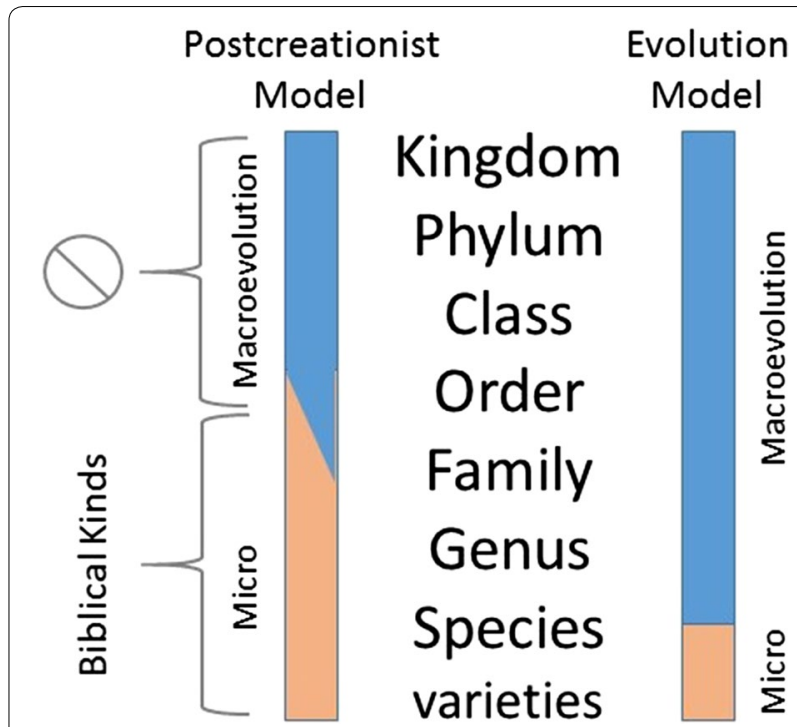

Fig. 6 The use of the terms micro- and macroevolution to changes that occur within different taxonomic categories according to the creationary and evolutionary models of biological change. Postcreationists believe that microevolutionary processes cannot accrue to result in divergences seen in higher taxonomic groupings (in fact such grouping don't make sense as clades since they were not unified by homologies via common ancestry) while many evolutionary biologists maintain that macroevolutionary patterns are an emergent property of continued microevolutionary processes occurring continuously within species

suggested that sea lions share a common ancestor with bears (Wise 2002, 2009). As mentioned previously, Lightner has speculated that some kinds were equivalent to the common ancestors of members of a whole taxonomic Order rather than families (Lightner 2012). For example, she and other creationists have speculated that all bats (Order Chiroptera) may be the same kind, likewise, all ruminants (unranked Ruminantia) may constitute a single kind. Wise (2002, 2009), has proposed that Noah may have brought a walking landliving whale ancestor on Noah's ark which then "diversified" into all the marine cetaceans that live today all in the space of less than 4500 years.

The confusion generated by the changing approach of postcreationists to the inclusivity of kinds is evident for those visiting the Ark Encounter. Walking through the attraction, visitors may be struck by the fact that few of the kinds depicted bear concrete resemblance to any creatures alive today. The attraction openly teaches that both giraffes and okapis evolved from a single shortnecked ancestral pair preserved on the Ark. Postcreationists make this claim despite formerly arguing for nearly a century that the long neck of the giraffe is an example of intentional, specific design and could not have evolved from any intermediate forms (Viett 2017). 
YECs have long used-or in some cases created-popular misconceptions of scientific terminology to redefine biological terminology and misrepresent evolutionary theory to their followers. Our carnivoran example illustrates that postcreationist attempts to clarify and systematize their redefinitions of biology, as exemplified in the Ark Encounter, have led them to embrace more tenets of evolutionary biology than most realize. In doing so, they risk their followers finding out that they are not as staunchly opposed to Darwinian evolution as they have always claimed.

\section{Opportunities and advantages of understanding postcreationism}

Although evolutionary biologists and science educators may understand the nuanced differences between the terms macroevolution and microevolution and may in fact not even use them in educational contexts, a lack of familiarity in the general public with applying these terms presents an opportunity for creationists to exploit the lack of commonly-understood definitions and substitute their own. Due in part to the efforts of postcreationists, "macroevolution" has been misrepresented with a single idea: common ancestry of all life. It brings to mind the image of molecules turning into man-goo becoming a zoo-and humans descended more immediately evolving from ape-like ancestors.

How can advocates for science address this form of science denialism? Should they even attempt to address it? One approach is to ignore or dismiss postcreationism as mere pseudoscience or minor fringe movement with few followers. Such an approach depends on the assumption that student exposure to post creationism will be limited. Yet more than 4 million visitors have already been exposed to postcreationist teaching at the Ark Encounter, and millions more have been exposed through the movement's social media, creation conferences, and books. Educators tasked with teaching the fundamental concepts of evolutionary biology can expect that some of their students will have encountered this material and therefore will approach the subject not only with some apprehension but with a conflicting set of understanding and implications of core concepts.

It may be sufficient to treat postcreationism as if it were exclusively a religious topic and thus not appropriate to discuss in class (Gould 1997). However, such reactions are almost certain to produce additional confusion and prevent students from gaining a greater understanding of evolutionary processes. Assuming that students will assimilate the "facts" that they are fed ignores the observation that some students will have rejected the "facts" a priori. They are driven by motivated rejection (Lewandowski and Oberauer 2016) promoting cognitive dissonance, in which they reject facts which they feel challenge their core beliefs whenever those beliefs are threatened.

There is a growing awareness of the need for better science communication (de Bruin and Bostrom 2013; Nisbet and Scheufele 2009; Miller 2016) and an increasing body of literature aimed at providing solutions (Oreskes and Conway 2010; Hornsey and Fielding 2017; Lewandowsky and Oberauer 2016; Lindsay et al. 2019; Schmid and Betsch 2019; Williamson 2016). Biology educators, especially those in secondary education, are at the forefront of the battle against science denialism and are therefore in a place to provide the first contact with students who have been exposed to non-consensus science and who may be driven by motivated rejection. But should they engage in rebutting science denialism? If so, how? Schmid and Betsch (2019) found that multiple forms of engagement including topic rebuttal and technique rebuttal yielded positive results but suggested that the latter is a more effective strategy for many science advocates. The former involves providing supporting data supporting the consensus view in direct contrast to the data presented by the denier. However, this requires the science advocate to be armed with specific information and thus is dependent on the level of expertise and their confidence (Schmid and Betsch 2019).

The latter form, technique rebuttal, involves uncovering the techniques or assumptions of the science denier. In the particular case of the denial of macroevolution, the denier is employing the use of alternative terminology to draw a safe space within which they can preserve their core beliefs or insecurities. This produces a status in which facts have a muted impact. Recognizing the source of tension and addressing the rhetoric and assumptions that have bound a student to their form of misconception or science denial allows a way forward. Using technique rebuttal, an instructor need not be well-versed in every detail of creationist theory but can use some basic knowledge of creationism, such as that provided here, to create a form of cognitive dissonance in students that might have certain preconceived notions of what they believe about evolution.

We should recognize that there are multiple forms of perceived "misconceptions", namely the difference between deeply rooted conceptions that run in opposition to scientific thought (such as those purported by postcreationists), and more tentative ideas that can be readily corrected through instruction (such as simple confusion over evolution concepts due to exposure to various mental models). Challenge arises when instructors must determine which form of misconception may be encountered and the resultant strategies employed (Maskiewicz and Lineback 2013). Entrenched 
young-earth creationists are not vulnerable to the topic rebuttal and will require more than just additional instruction. Instead, they need to be challenged with material that forms a tailored application of stepwise cognitive dissonance, shifting their own understanding stepwise towards the scientific consensus. In contrast, audiences which simply hold incomplete or inaccurate understandings of evolution can be better addressed with corrective informational instruction. Understanding the roots of misconceptions is fundamental to proper strategies to correct them (Senter and Mackey 2017).

For example, some students will have been raised on the idea that change within kinds is equivalent to microevolution. When it is suitable to address these misconceptions, an instructor can show that the student's own understanding of acceptable diversification is broad enough to include the mainstream understanding of macroevolution and therefore includes most planks of the evolutionary model. This revelation forces students to re-evaluate the limits of microevolution, rather than following the creationist view and reflexively dismissing evolutionary biology. They may wonder: if all canines could have evolved from a common ancestor, then what would limit felines and canines from having a common ancestor as well? If rapid speciation could have taken place in only a few dozen centuries, what sort of diversification would be possible over hundreds of millions of years?

We agree with Scott (2012) and others that answering creationism's falsehoods in a public education setting runs the risk of lending it an improper aura of legitimacy as an alternative to the scientific consensus. However, creationism is fundamentally distinct from other creation myths. There are no organized movements attempting to promote or develop scientific versions of the Hindu Nasadiya Sukta, the Norse Gylfaginning, or the earth-diver myths of Native American lore. No instructor will likely be confronted by a student sincerely arguing that continental plates formed when the goddess Gaia came to rest on top of the god Tartarus, as in the Greek Theogony. Yet the spread of creationism means instructors are increasingly likely to be challenged with claims that the Big Bang is flawed, that geology should be understood as the result of a global flood, and that biological evolution is baseless.

How might an instructor be prepared to answer such challenges without creating the appearance of a legitimate controversy? One possible solution would be to discuss various creation myths as an exploration of the scientific method and the fundamentals of falsifiability in science. Students could be asked to imagine what sort of evidence they would look for if they were trying to claim that a particular creation myth or origin story was somehow historically accurate. This exercise could serve as a springboard to providing actual examples of how earnest versions of this process have produced modern creationism, using illustrations from the Ark Encounter and other YEC literature. Such an exercise is not dissimilar from a discussion of Lamarck's view of inheritance of acquired characteristics as a contrast and precursor to Darwin's view of natural selection, or from a discussion of the spontaneous generation myth as a contrast to modern cell theory.

If undertaken, this exercise should not be unguided or open-ended. Instead, instructors should use postcreationism's growing acceptance of broad evolutionary principles to illustrate how persistent attempts to legitimize myth ultimately break down. We believe the example of carnivores presented here, specifically with respect to the origins of "cats" and "dogs", offers an excellent opportunity to demonstrate this breakdown while challenging any misconceptions students may already harbor about macroevolution and microevolution. The ultimate goal for instructors is to break the reflexive reticence to learn about evolutionary biology and cultivate honest curiosity.

A topic outline might take the following form:

1. Creation around the world: Exploring origin myths

2. Abusing the scientific method: Finding "evidence" for Norse/Greco-Roman/Native myth

3. Creating controversy: Modern creationism (via the Ark Encounter) as an attempt to legitimize myth

4. Cats and dogs: Is there a scientific line between "microevolution" and "macroevolution"?

5. Accidental evolutionist: How exploring real biology invariably leads to discovering evolutionary principles

Even if exercises like these are beyond the scope of a particular class, educators should be made aware that some of their students have already been exposed to creationism. Many of those students don't know what creationist theory teaches, beyond "evolution is bad" and "humans are not apes." If educators don't know any more about creationism than their students, it will be difficult for them to address the topic directly or indirectly. In many cases, simply being familiar with some basic postcreationist language demonstrates a capacity to engage the student, rather than appearing to be ignorant or uninformed.

\section{Conclusions}

Today, YECs stand as the chief anti-evolutionary voices in North America and across the globe. But young-earth creationism has evolved since it was reincarnated in early in the last century. It is important for educators to be aware that creationists have appropriated and mangled 
mainstream scientific terms in defense of their youngearth creationist biology and alternative natural history. We have identified and described an ideological movement within young-earth creationism we call postcreationism: a belief in hyperrapid speciation model of the origins of biological diversity. The example of carnivores presented here, offers an opportunity to challenge students' misconceptions about evolutionary models of the origins of biological diversity.

\section{Abbreviations \\ AiG: Answers in Genesis; OEC: Old Earth Creationist (ism); YEC: Young earth creationist (ism).}

\section{Acknowledgements}

We would like to thank students at the University of Akron for their feedback when presented with the concepts from this manuscript. We are also greatly indebted to reviewers who were very generous with their time providing many valuable improvements. In particular one reviewer with deep knowledge of YEC history provided a much needed reorienting of perspective in the final version.

\section{Authors' contributions}

RJD, TRB and DM all contributed to the intellectual development and writing of this manuscript. DM produced Figs. 4, 5 and 6. All authors read and approved the final manuscript.

\section{Funding}

None.

\section{Availability of data and materials}

The figures in this manuscript have been provided in PowerPoint format for anyone to download.

\section{Competing interests}

The authors declare that they have no competing interests.

\section{Author details \\ 1 Department of Biology, University of Akron, Akron, OH 44325-3908, USA. \\ 2 Department of Biological Sciences, Carnegie Mellon University, 4400 Fifth Avenue, Pittsburgh, PA 15213, USA. ${ }^{3}$ Columbus School of Law, Catholic Uni- versity of America, Washington, DC 20017, USA.}

Received: 19 October 2019 Accepted: 11 May 2020

Published online: 19 May 2020

\section{References}

Allmon WD. Taxic evolutionary paleoecology and the ecological context of macroevolutionary change. Evol Ecol. 1994;8(2):95-112.

Ark Encounter. How many bats were on Noah's Ark? Accessed from The Ark Encounter. https://arkencounter.com/blog/2016/06/23/how-many-batswere-on-noahs-ark/. Accessed 17 Mar 2020.

Belknap M, Chaffey T. Reimagining Ark Animals. Accessed from Answers in Genesis. https://answersingenesis.org/noahs-ark/reimagining-ark-anima Is/, Accessed 16 May 2019

Bergstrom CT, Dugatkin L. Evolution. 2nd ed. New York: Norton Publishers; 2016.

Bielo JS. Ark Encounter: the making of a creationist theme park. New York: NYU Press; 2018.

Chinn CA, Buckland LA. Differences in epistemic practices among scientists, young earth creationists, intelligent design creationists, and the scientist creationists of Darwin's era. In: Taylor R, Ferrari M, editors. Epistemology and science education: understanding the evolution vs. intelligent design controversy. New York: Taylor \& Francis; 2011. p. 38-76.
Cleland CE. Methodological and epistemic differences between historical science and experimental science. Philos Sci. 2002;69(3):447-51.

Currie A. Rock, bone, and ruin: an optimist's guide to the historical sciences. Cambridge: MIT Press; 2018.

de Bruin WB, Bostrom A. Assessing what to address in science communication. Proc Nat Acad Sci. 2013;110(Supplement 3):14062-8.

Duff RJ. A creation museum speaker asks: do animals evolve?. Historia Naturalis. 2016b. https://thenaturalhistorian.com/2016/08/12/a-creation-museu m-speaker-asks-do-animals-evolve/. Accessed 17 May 2019.

Duff RJ. Ark Encounter common ancestors: the increasing inclusiveness of Biblical kinds. Historia Naturalis. 2016a. https://thenaturalhistorian. com/2016/09/01/ark-encounter-common-ancestors-the-increasing-inclu siveness-of-biblical-kinds/. Accessed 17 May 2019.

Erwin DH. Macroevolution is more than repeated rounds of microevolution. Evol Dev. 2000;2(2):78-84.

Menton D. Natural selection and evolution. St. Louis MetroVoice. 1994:4(2) https://answersingenesis.org/natural-selection/natural-selection-andmacroevolution/. Accessed 15 May 2018.

Freeman S, Herron JC. Evolutionary analysis. 3rd ed. Upper Saddle River: Pearson Prentice Hall; 2004.

Futuyma DJ, Kirkpatrick M. Evolution. 4th ed. Sunderland: Sinauer Associates; 2017.

Geisler N, Anderson K. Origin science. Grand Rapids: Baker Book House; 1987.

Gould SJ. Nonoverlapping Magisteria. Nat Hist. 1997;106:16-22.

Grantham TA. HIERARCHICAL APPROACHES TO MACROEVOLUTION: recent work on species selection and the "effect hypothesis". Ann Rev Ecol Syst. 1995:26(1):301-21.

Ham K. [AigKenHam] The wolf \& coyote are different species \& evolutionists claim this took thousands of years, yet the differences between the Great Dane \& Yorkshire Terrier are much greater but they are the same species \& we know were bred in the last few hundred yrs. Evolution is bankrupt. https://twitter.com/aigkenham/status/973156054702882818. [Tweet] 12 Mar 2018.

Ham K. How many animals were on the Ark? https://answersingenesis.org/ media/audio/answers-with-ken-ham/volume-127/how-many-anima Is-were-on-ark/. Accessed 19 June 2019.

Heinrich RE, Strait SG, Houde P. Earliest Eocene Miacidae (Mammalia: Carnivora) from northwestern Wyoming. J Paleontol. 2008;82(1):154-62.

Hennigan T. An initial estimate toward identifying and numbering amphibian kinds within the orders Caudata and Gymnophiona. Answ Res J. 2013;6:17-34

Hennigan T. An initial estimate toward identifying and numbering extant tuatara, amphisbaena, and snake kinds. Answ Res J. 2014;7:31-47.

Hill H, Harrell IB, Rogers ME. From goo to you by way of the zoo. Grand Rapids: FH Revell Company; 1985 (Revised and updated).

Hornsey MJ, Fielding KS. Attitude roots and Jiu Jitsu persuasion: understanding and overcoming the motivated rejection of science. Am Psychol. 2017;72(5):459.

Jablonski D, Benton MJ, Gastaldo RA, Marshall CR, Sepkoski JJ. Macroevolution in the 21st century. In: Paleontology in the 21st century workshop: international senckenberg conference, Kleine Senckenbergreihe, vol. 25. 1997.

Jeanson NT. Mitochondrial DNA clocks imply linear speciation rates within "kinds". Answ Res J. 2015:8:273-304.

Jeanson NT, Lisle J. On the Origin of eukaryotic species, genetic clocks, population growth curves, and comparative nuclear genome analyses suggest created heterozygosity in combination with natural processes as a major mechanism. Answ Res J. 2016:9:81-122.

Jeffares B. Testing times: regularities in the historical sciences. Stud Hist Philos Sci Part C Stud Hist Philos Biol Biomed Sci. 2008;39(4):469-75.

Knight C. Ark Encounter reports 1 million visitors in second year. Cincinnati Enquirer 2018 July 6. https://www.cincinnati.com/story/ news/2018/07/05/ark-encounter-reports-1-million-visitors-2ndyear/759704002/. Accessed 20 June 2019.

Lewandowsky S, Oberauer K. Motivated rejection of science. Curr Dir Psychol Sci. 2016;25(4):217-22.

Lightner JK. Mammalian ark kinds. Answ Res J. 2012;5:151-204.

Lightner JK, Ahlquist J. Founder events: foundational in rapid post-flood diversification. Creat Res Soc Q. 2017;53(3):217-24.

Lightner JK, Hennigan T, Purdom G, Hodge B. Determining the Ark kinds. Answ Res J. 2011;4:195-201 
Lindsay J, Arok A, Bybee SM, Cho W, Cordero AM, Ferguson DG, Galante LL, Gill R, Mann M, Peck SL, Shively CL. Using a reconciliation module leads to large gains in evolution acceptance. CBE Life Sci Educ. 2019;18(4):ar58.

MacMillan D. Dodging Darwin: how Ken Ham's Ark encounter is slowly embracing evolution. Historia Naturalis. 2015. https://thenaturalhistorian. com/2015/12/30/dodging-darwin-how-ken-hams-ark-encounter-is-slowl y-embracing-evolution/. Accessed 7 July 2019.

Marsh FL. Fundamental biology. Lincoln NE: Author; 1941.

Maskiewicz AC, Lineback JE. Misconceptions are "so yesterday!". CBE Life Sci Educ. 2013;12(3):352-6.

Menton D. Is evolution a theory, a fact, or a law? —or none of the above? St Louis MetroVoice 1993:3(10). https://answersingenesis.org/theory-ofevolution/evolution-theory-fact-or-law/. Accessed 15 May 2019.

Miller JD. Civic scientific literacy in the United States in 2016. International Center for the Advancement of Scientific Literacy: Ann Arbor; 2016.

Morris HM. Scientific creationism. Green Forest: New Leaf Publishing Group; 1974.

Morris JD. What is the difference between macroevolution and microevolution? Acts \& Facts. 1996;25(10). https://www.icr.org/article/what-diffe rence-between-macroevolution-microevolut/.

Morris HM, Parker G. What is creation science?. Green Forest: New Leaf Publishing Group; 1982.

Morris HM, Whitcomb JC. The Genesis flood: the biblical record and its scientific implications. Phillipsburg: Presbyterian \& Reformed Publishing; 1961.

Nisbet MC, Scheufele DA. What's next for science communication? Promising directions and lingering distractions. Am J Bot. 2009;96(10):1767-78.

Novick LR, Schreiber EG, Catley KM. Deconstructing evolution education: the relationship between micro-and macroevolution. J Res Sci Teach. 2014;51(6):759-88.

Numbers RL. The creationists: from scientific creationism to intelligent design. Cambridge: Harvard University Press; 2006 (Revised and updated)

Numbers R, Lustig A, Richards R, Ruse M. Ironic heresy: how young-earth creationists came to embrace rapid microevolution by means of natural selection. 2004:84-100.

Nyakatura K, Bininda-Emonds ORP. Updating the evolutionary history of Carnivora (Mammalia): a new species-level supertree complete with divergence time estimates. BMC Biol. 2012;10(1):12. https://doi. org/10.1186/1741-7007-10-12.

Oreskes N, Conway EM. Defeating the merchants of doubt. Nature. 2010;465(7299):686

Osborne B. Do animals evolve. Lecture presented at: 2016: Creation Museum, Petersburg, Kentucky. https://www.facebook.com/AnswersInGenesis/ videos/10155180229564899/.

Patterson RT. Evolution exposed: your evolution answer book for the classroom. Answers in Genesis; 2008.

Price GM. The new geology: a textbook for colleges, normal schools, and training schools; and for the general reade. Oakland: Pacific Press Publishing Association; 1923

Rosenau J. "Historical science" vs. "Experimental science". National Center for Science Education. 2008. https://ncse.com/creationism/analysis/historical -science-vs-experimental-science. Accessed 20 May 2019.
Schmid P, Betsch C. Effective strategies for rebutting science denialism in public discussions. Nat Hum Behav. 2019;24:1.

Scott E. Foreword. In: Rosengren KS, Brem SK, Evans EM, Sinatra GM, editors. Evolution challenges: integrating research and practice in teaching and learning about evolution. Oxford: Oxford University Press; 2012.

Senter P. Using creation science to demonstrate evolution: application of a creationist method for visualizing gaps in the fossil record to a phylogenetic study of coelurosaurian dinosaurs. J Evol Biol. 2010;23(8):1732-43.

Senter PJ, Mackey JJ. The evolution of creation science, part 1: vestigial structures and biological degeneration. Perspect Sci Christian Faith. 2017;69(1):27.

Stanley SM. Macroevolution: pattern and process. San Francisco: W.H. Freeman and Company; 1979.

UC Berkeley website. Understanding evolution, page what is macroevolution. https://evolution.berkeley.edu/evolibrary/article/evo_48. Accessed 5 Jan 2019.

Viett K. Giraffes: towering testimonies to God's design. 2017. https://answe rsingenesis.org/mammals/giraffes-towering-testimonies-to-gods-desig n/. Accessed 15 May 2019

We believe in dinosaurs. USA: 137 Films; 2019

Whorton MS. Peril in paradise: theology, science, and the age of the earth. Westmont: InterVarsity Press; 2005.

Williamson P. Take the time and effort to correct misinformation. Nat News. 2016;540(7632):171.

Wise KP. Faith, form, and time: what the bible teaches and science confirms about creation and the age of the universe. Nashville: B\&H Publishing Group; 2002.

Wise KP. Mammal kinds: how many were on the Ark. CORE Issues Creat. 2009:5:129-61.

Wise KP. Baraminology: a young-earth creation biosystematic method. In: Proceedings of the second international conference on creationism. Vol. 2. Pittsburgh, PA: Creation Sci. Fellowship, Inc.; 1990. p. 345-60.

Wood TC. The current status of baraminology. Creat Res Soc Q. 2006;43(3):149-58

Wood TC. Mitochondrial DNA analysis of three terrestrial mammal baramins (Equidae, Felidae, and Canidae) implies an accelerated mutation rate near the time of the Flood. In: Proceedings of the seventh international conference on creationism. 2013.

Wood TC, Garner PA, editors. Genesis kinds creationism and the origin of species. Eugene: Wipf and Stock Publishers; 2009.

Wood TC, Wise KP, Sanders R, Doran N. A refined baramin concept. Occasional Papers of the BSG. 2003:3:1-4.

Woodmorappe J. Noah's ark: a feasibility study. Dallas: Institute for Creation Research; 1996

Zimmer C, Emlen DJ. Evolution: making sense of life. New York: Macmillan Higher Education; 2015.

\section{Publisher's Note}

Springer Nature remains neutral with regard to jurisdictional claims in published maps and institutional affiliations.
Ready to submit your research? Choose BMC and benefit from:

- fast, convenient online submission

- thorough peer review by experienced researchers in your field

- rapid publication on acceptance

- support for research data, including large and complex data types

- gold Open Access which fosters wider collaboration and increased citations

- maximum visibility for your research: over 100M website views per year

At BMC, research is always in progress.

Learn more biomedcentral.com/submissions 